\title{
Affect Sequences and Learning in Betty's Brain
}

\author{
Juliana Ma. Alexandra \\ L. Andres \\ University of Pennsylvania \\ 3700 Walnut Street \\ Philadelphia, PA 19104 \\ aandres@gse.upenn.edu
}

\author{
Jaclyn Ocumpaugh \\ University of Pennsylvania \\ 3700 Walnut Street \\ Philadelphia, PA 19104 \\ ojaclyn@upenn.edu
}

\author{
Ryan S. Baker \\ University of Pennsylvania \\ 3700 Walnut Street \\ Philadelphia, PA 19104 \\ rybaker@upenn.edu
}

\author{
Stefan Slater \\ University of Pennsylvania \\ 3700 Walnut Street \\ Philadelphia, PA 19104 \\ slater.research@gmail.com
}

\author{
Luc Paquette \\ University of Illinois at \\ Urbana-Champaign \\ 1310 S. Sixth St. \\ Champaign, IL 61820 \\ lpaq@illinois.edu
}

\author{
Yang Jiang \\ Columbia University \\ 116th St \& Broadway \\ New York, NY 10027 \\ yj2211@tc.columbia.edu
}

\author{
Shamya Karumbaiah \\ University of Pennsylvania \\ 3700 Walnut Street \\ Philadelphia, PA 19104 \\ shamya@gse.upenn.edu
}

\author{
Nigel Bosch \\ University of Illinois at \\ Urbana-Champaign \\ 1310 S. Sixth St. \\ Champaign, IL 61820 \\ pnb@illinois.edu
}

\author{
Anabil Munshi \\ Vanderbilt University \\ 2201 West End Ave, \\ Nashville, TN 37235 \\ anabil.munshi@vanderbilt.edu
}

\author{
Allison Moore \\ Vanderbilt University \\ 2201 West End Ave, \\ Nashville, TN 37235 \\ allison.1.moore@vanderbilt.edu
}

\author{
Gautam Biswas \\ Vanderbilt University \\ 2201 West End Ave, \\ Nashville, TN 37235 \\ gautam.biswas@vanderbilt.edu
}

\begin{abstract}
Education research has explored the role of students' affective states in learning, but some evidence suggests that existing models may not fully capture the meaning or frequency of how students transition between different states. In this study we examine the patterns of educationally-relevant affective states within the context of Betty's Brain, an open-ended, computer-based learning system used to teach complex scientific processes. We examine three types of affective transitions based on similarity with the theorized D'Mello and Graesser model, transition between two affective states, and the sustained instances of certain states. We correlate of the frequency of these patterns with learning outcomes and our findings suggest that boredom is a powerful indicator of students' knowledge, but not necessarily indicative of learning. We
\end{abstract}

Permission to make digital or hard copies of all or part of this work for personal or classroom use is granted without fee provided that copies are not made or distributed for profit or commercial advantage and that copies bear this notice and the full citation on the first page. Copyrights for components of this work owned by others than ACM must be honored. Abstracting with credit is permitted. To copy otherwise, or republish, to post on servers or to redistribute to lists, requires prior specific permission and/or a fee. Request permissions from Permissions@acm.org.

LAK19, March, 2019, Tempe, AZ, USA

(C) 2019 Association for Computing Machinery. ACM ISBN 978-1-4503-6256-6/19/03 ...\$15.00

https://doi.org/10.1145/3303772.3303807 discuss our findings within the context of both research and theory on affect dynamics and the implications for pedagogical and system design.

\section{CCS CONCEPTS}

- Applied computing Computer-managed instruction • Applied computing Computer-assisted instruction

\section{KEYWORDS}

Affect dynamics, affect, learning analytics

ACM Reference format:

F. Lname, F. Lname, and F. Lname. 2019. Affect Sequences and Learning in Betty's Brain. In The $9^{\text {th }}$ International Learning Analytics \& Knowledge Conference (LAK19), March, 2019, Tempe, AZ, USA. ACM, New York, NY, USA. 8 pages. DOI: https://doi.org/10.1145/3303772.3303807

\section{INTRODUCTION}

The affective processes associated with learning are increasingly of interest to researchers who are trying to understand how students regulate their learning processes [7, 11, 34]. Many studies have examined how students transition between affective states while engaged in learning activities $[1,11,23,24,27,29,32,33]$, including several that compare these patterns to performance outcomes and learning gains $[5,11,12,14,22]$. Most studies have 
focused on affective states that are thought to be educationally relevant $[\mathrm{cf} .7,30]$ including boredom (BOR), confusion (CON), engaged concentration (ENG; sometimes labeled flow), delight (DEL), frustration (FRU), and surprise.

One of the more influential papers in this field, D'Mello and Graesser [11], hypothesized two main pathways that students follow when transitioning between affective states: one that encourages learning (the $E N G-C O N-D E L-E N G$ cycle) and one that inhibits it (the $E N G-C O N-F R U-B O R$ cycle). However, based on analyses of their data (calculating the likelihood of a transition from one affective state to another), they then proposed a more succinct model.

Since this pioneering work, a substantial body of research has investigated these issues, many following the same methodological approach that analyzes the frequency of two-step transitions, (e.g., from confusion to frustration; denoted as $C O N-F R U$ ) rather than patterns involving multiple transitions (e.g., the $E N G-C O N-F R U$ $B O R$ cycle). [PROBABLY NEEDS ANOTHER SENTENCE HERE]

The current study uses sensor-free, interaction-based detectors (e.g., [2]) previously developed for the Betty's Brain [18] to explore the relationship between affective patterns and learning outcomes (measured using pre- and post-tests of content knowledge). Specifically, we compare the four-step patterns originally proposed in D'Mello and Graesser [11] to shorter patterns involving three steps, but only two affective states (e.g., BOR-BOR-CON). We then compare these results to patterns involving off-task behavior as well as to sustained instances of two affective states (boredom and delight) that appear repeatedly in statistically significant multi-state patterns. These results suggest that affective patterns in Betty's Brain may more strongly reflect prior knowledge than learning, which has implications for the design of affective-driven interventions.

\section{PREVIOUS RESEARCH}

D'Mello and Graesser [11] investigated theoretically-motivated affective cycles by studying the two-step transitions within them (i.e., ENG-CON, CON-DEL, DEL-ENG, CON-FRU, and FRU$B O R)$. After synthesizing this data, their revised theoretical model (shown in Figure 1) no longer included delight, but instead focused on transitions between engaged concentration, confusion, frustration, and boredom.

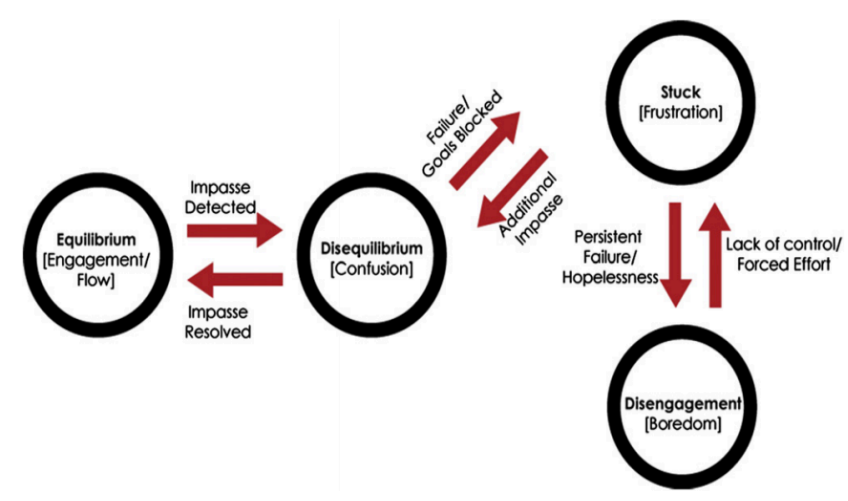

Figure 1: D'Mello \& Graesser's [11] model of affect dynamics

Other studies examine patterns of longer lengths. In Cognitive Tutor Algebra, Liu et al. [22] explored three-step affect transitions involving the presence or absence of confusion and frustration (e.g., CON-Not-CON or FRU-FRU-Not). In this study, patterns where all three steps were labeled with one of these affective states (e.g., $C O N-C O N-C O N$ or FRU-FRU-FRU) were negatively correlated with learning, but so was the absence of either emotion (i.e., NotNot-Not).

More recent work in affect dynamics [19] has looked at how the operationalization of these measurements may influence which transitions emerge as statistically significant, focusing on the implementation of D'Mello's $L$ - the metric introduced by D'Mello and colleagues $[9,11]$, to calculate the likelihood that a transition from one affective state to the next will occur, given the base rates observed for each. Previous analyses showed that the exclusion of self-transitions (e.g., $C O N-C O N$ ) when calculating D'Mello's $L$ can inflate the number of statistically significant transitions. However, even when this adjustment was made, not all hypothesized patterns were seen, either in Karumbaiah et al. [19] or in D'Mello and Graesser's original paper [9].

Moreover, the use of D'Mello's $L$, as currently defined, limits research to investigations of two-step patterns. Using an expanded list of affective patterns and longer sequences allows for the discovery of meaningful affective experiences while accounting for the varying lengths of emergence of different states.

\section{Betty's Brain}

Betty's Brain is an open-ended, computer-based learning system that uses a learning-by-teaching paradigm to teach complex scientific processes [21]. Betty's Brain asks students to teach a virtual agent (Betty) about scientific phenomena (e.g., climate change, ecosystems, thermoregulation) by constructing concept maps that demonstrate the causal relationships involved (see Figure 2.)

The learning process required by Betty's Brain necessitates high levels of self-regulation. As students construct their map, they must navigate through multiple hypermedia information sources where they can read about a variety of subthemes. They choose how often to test Betty's knowledge, and they may elect to interact with a virtual mentor agent (an experienced teacher named Mr. Davis) if 
they are having trouble teaching Betty. Because of these design factors, strong self-regulated learning behaviors are crucial for succeeding within Betty's Brain.

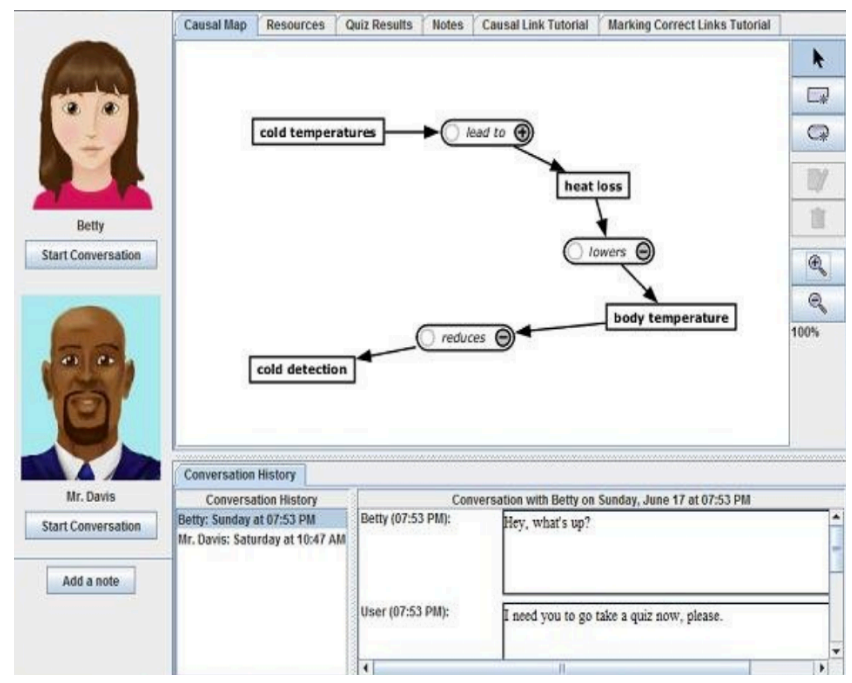

Figure 2: Screenshot showing the construction of a concept map (right) being used to teach the student agent (Betty, top left), with help from the mentor-agent (Mr. Davis, bottom left).

These pedagogical agents provide a social framework for the gradual internalization of effective learning behaviors [e.g., 29, 35], and an emphasis on self-regulatory feedback that has been demonstrated to improve these behaviors among students who use Betty's Brain [21]. However, to date, less work has been done on how students' affective states may be playing a role in this process.

\section{Methods}

\subsection{Study Design}

This study uses data from 93 sixth graders who used Betty's Brain during the 2016-2017 school year during their science classes in an urban public school in Tennessee. Data were collected over the course of seven school days. On the first day of the study, students completed a 30-45-minute paper-based pre-test that measured knowledge of scientific concepts and causal relationships. On day 2, students participated in a 30-minute training session that familiarized them with the learning goals and user interface of the software. Following the pre-test and training, students used the Betty's Brain software on days 2 through 6, for approximately 4550 minutes each session, using concept maps to teach Betty about the causal relationships involved in the process of climate change. On day 7 , students completed a post-test that was identical to the pre-test, in order to assess changes in knowledge based on working with Betty's Brain for the week.

\subsection{BROMP Observations \& Detectors}

Students' affect was assessed using a model-based approach that employed the Baker Rodrigo Ocumpaugh Monitoring Protocol
(BROMP) [26]. These were developed using established methods and that have been previously published.

4.2.1 BROMP Observations. The Baker Rodrigo Ocumpaugh Monitoring Protocol (BROMP) is a method for conducting Quantitative Field Observations (QFOs) of student behavior and affect [26]. BROMP is primarily used to develop sensor-free detectors [3], but has been used for other purposes as well (e.g., [2]).

Within BROMP, students are observed using a momentary time sampling method [25], where students are repeatedly coded individually, in a predetermined order. This sampling method is designed to achieve a representative sample of behavior and affect among the students while reducing the tendency to focus on more extreme events. Both affect and behavior are recorded separately, but simultaneously, in each observation. Typical coding categories include boredom, confusion, engaged concentration, delight, and frustration (for affective states) and on task, on task-conversation, and off-task (for behaviors).

4.2.2 BROMP-based Detectors. BROMP-based detectors have now been developed for over a dozen intelligent tutoring systems. In this process, codes generated by BROMP-certified observers are matched to student log files, and then machine-learning techniques are used to generate classifiers for each affective state or behavioral category based on the students' interactions with the log files (e.g., [2]).

The detectors used in this study were previously developed for Bettys Brain by Jiang et al. [18]. These detectors, generated using either logistic or step regression, were evaluated using $\mathrm{A}^{\prime}$. Their performance under 10 -fold student-level cross-validation using AUC ROC (summarized in Table 1).

Table 1: Affect and behavior detector performance [18]

\begin{tabular}{lc}
\hline Affect/Behavior & AUC ROC \\
\hline Boredom & 0.682 \\
Confusion & 0.568 \\
Delight & 0.570 \\
Engaged Concentration & 0.624 \\
Frustration & 0.634 \\
Off-Task Behavior & 0.725 \\
\hline
\end{tabular}

For the purposes of this study, which focuses on affective transitions, only one behavior detector (off-task) is applied to the data. It is included so that we can compare negative effects of boredom to this detector for additional validity in our findings 4.2.2 Field Observations vs. Detectors. Detector performance is generally not as high as interrater reliability between two trained human coders. However, it does offer a significant advantage in terms of grain-size and scale. That is, with BROMP-base detectors, model labels are generated every 20 seconds for each detector. In contrast, BROMP field observers use a momentary time sampling procedure rather than observing the same student rapidly in succession. Thus, the time between field observations of a single 
student can sometimes be as high as several minutes, depending on how many students are being observed and what is happening in the classroom. .

\subsection{Prevalence of Affective Patterns}

The frequency of specific affective and behavioral patterns was calculated for each student. This process required several steps.

4.3.1 Applying Detectors. First, the BROMP-based detectors were applied to the log data for every student in the study. Each of the automated detectors was applied at the level of 20-second clips in the log data, producing a confidence value for each clip. Clips with a confidence value of at least $50 \%$ were labelled with the corresponding affective state. In the case where multiple detectors provided positive labels to a single log-file clip, all labels were applied, and multiple patterns were considered.

Of the 53,087 clips in this study, 17,585 were labeled as bored (33\%), 8,683 were labeled as confused (16\%), 34,934 were labeled as engaged concentration (66\%), 25,069 were labeled as delighted (47\%), 6,200 were labeled as frustrated (12\%), and 2,335 received no affective labels (4\%). Predictions for off-task behavior were made using the same method, but separately from affective state labels, resulting in 22,537 clips labeled as off-task (42\%). After all six detectors were applied, each 20-second clip contained a prediction from each detector (e.g., bored or not; confused or not; off-task or not; etc.); as such, the sum of the labels across all six detectors is greater than the total number of clips.

4.3.2 Pattern Types. In our analyses we focus on three types of affect pattern. Each involved a sequence of either three or four 20 second log-file clips. First, we looked at sequences that mirror the two cycles outlined by D'Mello \& Graesser [11]: the ENG-CON$D E L-E N G$ cycle and the ENG-CON-FRU-BOR cycle. For the purposes of this study, we have limited the analysis to 80 second (four-clip) versions of these cycles.

Next, we considered transitions between two states. For these analyses, we looked for a student having at least two consecutive clips with the same affective state predictions, before then transitioning to a second state (e.g., ENG-ENG-BOR or CON-CON$F R U$ ). These durations allow us to explore the potential effect that a longer duration (two or more steps) of any given antecedent might have on the subsequent steps in a sequence. Thus, we are able to explore the possibility that affective states of a longer duration (more than one successive step) might be influencing the results seen for sequences involving multiple transitions without testing all possible durations.

Finally, we consider sustained instances of two affective states that seemed to be driving the other patterns of statistical significance in this study. These are operationalized as 4-clip sequences (BOR-BOR-BOR-BOR and DEL-DEL-DEL-DEL), which we compare to sustained off-task behavior (OFF-OFF-OFF$O F F)$.

4.3.3 Prevalence Calculations. Once the data from Betty's Brain was fully labeled, we calculated the prevalence of each affective pattern within each student's log files. Because we are interested in multi-step transitions, we use a prevalence calculation (as opposed to D'Mello's $L$, which is more common in the affect dynamics literature, but which is designed to study only 2-clip patterns).

In this study, prevalence is the total number of times a pattern occurred within a given student's data $\left(\mathrm{O}_{a c t}\right)$ divided by the total number of times it could have occurred in that data $\left(\mathrm{O}_{p o s}\right)$. Because we consider the possibility of overlapping sequences, we calculate $\mathrm{O}_{p o s}$ by considering the total number of clips in a pattern $\left(\mathrm{C}_{p a t}\right)$ and the total number of clips in the student's data $\left(\mathrm{C}_{s t u}\right)$.

\section{Equation 1.}

$$
\text { prevalence }=\frac{\text { Oact }}{\text { Opos }} \equiv \frac{\text { Oact }}{\mathrm{Cstu}-(\mathrm{Cpat}-1)}
$$

For example, consider the calculation of Sustained $B O R$ (operationalized as $B O R-B O R-B O R-B O R$ ) for a student whose total data consisted of the following 7-clip sequence: FRU-BOR-BOR$B O R-B O R-B O R-C O N$. For this student, $\mathrm{O}_{a c t}=2$, since Sustained BOR is observed two times, from the $2^{\text {nd }}$ to the $5^{\text {th }}$ clip and from the $3^{\text {rd }}$ to the $6^{\text {th }}$ clip. Meanwhile, $\mathrm{C}_{s t u}=7$ (the total number of clips in the student's data) and $\mathrm{C}_{p a t}=4$ (since it is a 4-clip pattern), so that $\mathrm{O}_{p o s}=3$. Therefore, prevalence of Sustained BOR in this student's data is $2 / 4$ or $50 \%$.

Were we interested in a 3-clip pattern like BOR-BOR-CON for the same students' data, the calculation would be as follows:

$$
\frac{\text { Oact }}{\text { Cstu }-(\text { Cpat }-1)}=\frac{1}{7-(3-1)}=\frac{1}{5}=20 \%
$$

\section{Equation 2.}

Because it is possible for one clip to be labeled with more than one affect, it is possible to have multiple different affective patterns within the same number of clips. For instance, BOR-BOR-BOR$B O R / F R U$ would be counted as both Sustained BOR and the affective transition $B O R-F R U$.

\subsection{Statistical Analysis}

Spearman's Rho was used to correlate the prevalence of each affective state pattern to pre-test, post-test, and normalized gain scores calculated as (post-pre)/(1-pre) [15]. While a gain score measures the difference between pre-test and post-test, the normalized gain score measures this difference relative to the maximum possible improvement given a student's pre-test score. Spearman's Rho is a non-parametric correlation coefficient, and it is commonly used in analyses where assumptions of normality are not met across an entire feature space.

Because correlating each affective pattern against each of our three outcome measures resulted in 81 separate statistical tests, Benjamini and Hochberg's [4] post-hoc FDR correction was used to adjust the significance criterion across multiple tests. P-values in the results section are only marked as significant if they remained significant after this correction was applied.

\section{RESULTS AND DISCUSSION}




\subsection{Pattern Frequencies}

Affective patterns are described in Table 3, which summarizes the observation period and frequency for patterns involving boredom (BOR), confusion (CON), delight (DEL), engaged concentration (ENG), and frustration (FRU).

Table 3: Affect pattern frequencies

\begin{tabular}{llrr}
\hline Pattern & Obs. Period (sec) & $\mathbf{N}$ & \multicolumn{1}{c}{ Freq. } \\
\hline ENG-CON-FRU-BOR & $20-20-20-20$ & 173 & $0.30 \%$ \\
ENG-CON-DEL-ENG & $20-20-20-20$ & 1,678 & $3.20 \%$ \\
\hline ENG-BOR & $40-20$ & 7,964 & $15.00 \%$ \\
ENG-CON & $40-20$ & 3,774 & $7.11 \%$ \\
ENG-DEL & $40-20$ & 15,834 & $29.83 \%$ \\
ENG-FRU & $40-20$ & 1,972 & $3.71 \%$ \\
\hline BOR-CON & $40-20$ & 1,871 & $3.52 \%$ \\
BOR-DEL & $40-20$ & 5,866 & $11.05 \%$ \\
BOR-ENG & $40-20$ & 7,789 & $14.67 \%$ \\
BOR-FRU & $40-20$ & 1,006 & $1.90 \%$ \\
\hline CON-BOR & $40-20$ & 2,096 & $3.95 \%$ \\
CON-DEL & $40-20$ & 3,423 & $6.45 \%$ \\
CON-ENG & $40-20$ & 3,902 & $7.35 \%$ \\
CON-FRU & $40-20$ & 2,224 & $4.19 \%$ \\
\hline DEL-BOR & $40-20$ & 5,755 & $10.84 \%$ \\
DEL-CON & $40-20$ & 3,094 & $5.83 \%$ \\
DEL-ENG & $40-20$ & 14,329 & $26.99 \%$ \\
DEL-FRU & $40-20$ & 1,318 & $2.48 \%$ \\
\hline FRU-BOR & $40-20$ & 1,189 & $2.24 \%$ \\
FRU-CON & $40-20$ & 2,421 & $4.56 \%$ \\
FRU-DEL & $40-20$ & 1,736 & $3.27 \%$ \\
FRU-ENG & $40-20$ & 2,614 & $4.92 \%$ \\
\hline Sustained BOR & 80 & 11,759 & $22.15 \%$ \\
Sustained DEL & 80 & 16,219 & $30.55 \%$ \\
Sustained OFF & 80 & 10,155 & $19.13 \%$ \\
OFF-ENG & $40-20$ & 7,750 & $14.60 \%$ \\
\hline
\end{tabular}

The most frequently observed affective pattern in our data is sustained delight (33\%), followed by ENG-DEL (29.83\%), DELENG (26.99\%), Sustained BOR (22.15\%), and Sustained OFF (19.3\%). The two cycles hypothesized by D'Mello \& Graesser [10] occur relatively infrequently $(0.3 \%$ and $3.2 \%)$. In fact, all but three of the patterns occur more frequently than these two cycles: $B O R$ FRU (1.9\%), DEL-FRU (2.48\%), and FRU-BOR (2.24\%). The relative infrequency of the hypothesized cycles, however, may be due to methodological differences between these studies, specifically our decision to look at 20-second intervals rather than to collapse all repeated instances of a given emotion into a single unit of observation.

It is worth noting, however, that these analyses are being conducted on indirect measures of affective states. While our detectors have undergone a careful cross-validation process, these results should be interpreted carefully. In particular, the detector for delight appears to over-predict the prevalence of this affective state [18]. However, as the results presented below suggest, the student actions associated with delight appear to be highly relevant to understanding knowledge and learning behaviors.

\subsection{Correlations with Pre-test Scores}

As Table 4 shows, 9 of the 26 affective patterns in this study were significantly negatively correlated with pre-test scores. These include the inhibitory cycle hypothesized by D'Mello \& Graesser (ENG-CON-FRU-BOR, $\rho=-.239$ ), though it was rare, accounting for only . $3 \%$ of the 4 -clip sequences in the data.

Table 4: Correlations between affect patterns and pre-test scores

\begin{tabular}{|c|c|c|}
\hline Pattern & $\rho$ & Sig. (2-tailed) \\
\hline ENG-CON-FRU-BOR & $-.239 *$ & 0.026 \\
\hline ENG-CON-DEL-ENG & 0.209 & 0.052 \\
\hline ENG-BOR & $-.434 * *$ & $<0.001$ \\
\hline ENG-CON & -0.002 & 0.985 \\
\hline ENG-DEL & 0.194 & 0.081 \\
\hline ENG-FRU & -0.011 & 0.921 \\
\hline BOR-CON & $-.239 *$ & 0.026 \\
\hline BOR-DEL & $-.336 * *$ & 0.001 \\
\hline BOR-ENG & $-.449 * *$ & $<0.001$ \\
\hline BOR-FRU & $-.262 *$ & 0.014 \\
\hline CON-BOR & -0.137 & 0.207 \\
\hline CON-DEL & 0.081 & 0.458 \\
\hline CON-ENG & 0.063 & 0.561 \\
\hline CON-FRU & -0.036 & 0.739 \\
\hline DEL-BOR & -0.106 & 0.345 \\
\hline DEL-CON & 0.063 & 0.574 \\
\hline DEL-ENG & 0.197 & 0.076 \\
\hline DEL-FRU & 0.05 & 0.657 \\
\hline FRU-BOR & -0.17 & 0.116 \\
\hline FRU-CON & -0.045 & 0.687 \\
\hline FRU-DEL & -0.076 & 0.495 \\
\hline FRU-ENG & 0.06 & 0.579 \\
\hline Sustained BOR & $-.450 * *$ & $<0.001$ \\
\hline Sustained DEL & 0.195 & 0.07 \\
\hline
\end{tabular}




\begin{tabular}{lcc} 
Sustained OFF & $-.376^{* *}$ & $<0.001$ \\
OFF-ENG & $-.220 *$ & 0.041 \\
\hline
\end{tabular}

Like D'Mello and Graesser's [11] inhibitory cycle (ENG-CON$F R U-B O R$ ), six of the other significant patterns that are negatively correlated with pre-test scores also include boredom (ENG-BOR, BOR-CON, BOR-DEL, BOR-ENG, BOR-FRU, and Sustained $B O R$ ). This suggests that students who begin the activity with low knowledge are more likely to experience boredom. In fact, boredom patterns are even more likely ( $\rho=-.239$ to -.450$)$ among low-knowledge learners than off-task behaviors (Sustained OFF, $\rho=-.376)$.

\subsection{Correlations with Post-test Scores}

Correlations between affective state transitions and post-test scores are presented in Table 5, which shows patterns similar to those found in the pre-test results. However, this time, the role of delight is more pronounced.

Table 5: Correlations between affect patterns and post-test scores

\begin{tabular}{lcc}
\hline Pattern & $\rho$ & Sig. (2-tailed) \\
\hline ENG-CON-FRU-BOR & $-\mathbf{. 3 0 8 * *}$ & $\mathbf{0 . 0 0 4}$ \\
ENG-CON-DEL-ENG & $.214^{*}$ & 0.046 \\
\hline ENG-BOR &.$- .443 * *$ & $<\mathbf{0 . 0 0 1}$ \\
ENG-CON & -0.003 & 0.976 \\
ENG-DEL & 0.19 & 0.087 \\
ENG-FRU & 0.038 & 0.736 \\
\hline BOR-CON & $\mathbf{- . 3 5 0 * *}$ & $\mathbf{0 . 0 0 1}$ \\
BOR-DEL & $\mathbf{- . 3 8 9 * *}$ & $<\mathbf{0 . 0 0 1}$ \\
BOR-ENG &.$- .468 * *$ & $<\mathbf{0 . 0 0 1}$ \\
BOR-FRU & $\mathbf{- . 2 9 4 * *}$ & $\mathbf{0 . 0 0 6}$ \\
\hline CON-BOR & $-.224 *$ & $\mathbf{0 . 0 3 7}$ \\
CON-DEL & 0.082 & 0.448 \\
CON-ENG & 0.073 & 0.499 \\
CON-FRU & -0.039 & 0.719 \\
\hline DEL-BOR & -0.096 & 0.393 \\
DEL-CON & 0 & 0.999 \\
DEL-ENG & 0.18 & 0.105 \\
DEL-FRU & 0.092 & 0.411 \\
\hline FRU-BOR & -0.191 & 0.076 \\
FRU-CON & -0.031 & 0.783 \\
FRU-DEL & -0.051 & 0.65 \\
FRU-ENG & -0.042 & 0.698 \\
\hline & & \\
\hline & & \\
\hline
\end{tabular}

\begin{tabular}{lcc} 
Sustained BOR & $-.505 * *$ & $<0.001$ \\
Sustained DEL & $.300 * *$ & 0.005 \\
Sustained OFF & $-.512 * *$ & $<0.001$ \\
OFF-ENG & $-.307 * *$ & 0.004 \\
\hline
\end{tabular}

Two of these are positive correlations for the patterns $E N G$ CON-DEL-ENG $(\rho=.214)$ and Sustained DEL $(\rho=.300)$. These positive correlations suggest that increases in the frequency of these patterns would relate to an increase in post-test scores as well. By contrast, ten patterns show negative correlations. Five of these patterns begin with boredom, two with off-task behavior (Sustained $O F F, \rho=-.512 ; O F F-E N G, \rho=-.307)$, two with engaged concentration (ENG-CON-FRU-BOR, $\rho=-.308 ; E N G-B O R$, $\rho=-.443)$, and one with confusion (CON-BOR, $\rho=-.224)$. No significant correlations were found for 3 -step patterns beginning with either delight or frustration.

Overall, 8 of the significant patterns involve boredom. These include several patterns that were significantly negatively correlated with pre-test scores, including D'Mello and Graesser's negative cycle $(E N G-C O N-F R U-B O R, \rho=-.308)$ and the six other boredom-related patterns (ENG-BOR, BOR-CON, BOR-DEL, $B O R-E N G, B O R-F R U$, and Sustained BOR). In these cases, the strength of the correlations have all increased. The same is true for $C O N-B O R$, which was not significantly correlated with pre-test scores, but which is significantly correlated with post-test scores $(\rho=-.224)$.

\subsection{Correlations with Learning Gains}

Table 6 summarizes the correlations between affect patterns and learning gains. In contrast with pre-and post-test scores, only one significant correlation was found, suggesting that in this case affective states may be more closely tied to student knowledge than to student learning.

Curiously, the only pattern associated with higher learning gains is Sustained DEL (DEL-DEL-DEL-DEL, $\rho=.335)$, which was a pattern that was significantly correlated with higher post-test scores but not with prior knowledge. This result corresponds to the finding that the $E N G-C O N-D E L-E N G$ cycle was also correlated with posttest, but not pre-test scores; this cycle was not correlated significantly to learning gain, although there was a trend in that direction that may be worth further investigation.

Table 6: Correlations between affect patterns and learning gains

\begin{tabular}{lcc}
\hline Pattern & $\rho$ & Sig. (2-tailed) \\
\hline ENG-CON-FRU-BOR & -0.086 & 0.397 \\
ENG-CON-DEL-ENG & 0.141 & 0.162 \\
\hline ENG-BOR & -0.002 & 0.981 \\
ENG-CON & -0.02 & 0.847 \\
ENG-DEL & 0.01 & 0.927 \\
ENG-FRU & 0.043 & 0.681 \\
\hline
\end{tabular}




\begin{tabular}{lcc} 
BOR-CON & -0.13 & 0.197 \\
BOR-DEL & -0.036 & 0.719 \\
BOR-ENG & -0.028 & 0.782 \\
BOR-FRU & -0.098 & 0.332 \\
\hline CON-BOR & -0.032 & 0.753 \\
CON-DEL & 0.095 & 0.347 \\
CON-ENG & 0.112 & 0.269 \\
CON-FRU & 0.074 & 0.466 \\
\hline DEL-BOR & 0.05 & 0.635 \\
DEL-CON & -0.053 & 0.614 \\
DEL-ENG & 0 & 0.999 \\
DEL-FRU & 0.055 & 0.601 \\
\hline FRU-BOR & -0.07 & 0.488 \\
FRU-CON & 0.042 & 0.685 \\
FRU-DEL & -0.006 & 0.954 \\
FRU-ENG & -0.106 & 0.296 \\
\hline Sustained BOR & -0.099 & 0.328 \\
Sustained DEL & $\mathbf{3 3 5 * *}$ & $\mathbf{0 . 0 0 1}$ \\
Sustained OFF & -0.09 & 0.374 \\
OFF-ENG & 0.012 & 0.903 \\
\hline
\end{tabular}

\subsection{Summary of Results}

Even after the use of Benjamini and Hochberg's [4] post-hoc control, 22 of the 81 tested correlations produced significant results. Eighteen of these results emerged from only nine affective patterns (BOR-CON, BOR-DEL, BOR-ENG, BOR-FRU, FLOCON-FRU-BOR, ENG-BOR, OFF-ENG, Sustained BOR, Sustained $O F F$ ), which were negatively correlated with both preand post-test scores. One other pattern $(C O N-B O R)$ was also negatively associated with post-test scores. None of these patterns, however, were correlated with learning gains, a result which highlights the role of prior knowledge in the manifestation of affective patterns.

Only three of the significant correlations were positively associated with our outcome measures, and notably both involved the affective state of delight. D'Mello's ENG-CON-DEL-ENG was positively associated with post-test scores (but not pre-test scores or learning gains). Sustained DEL was significantly correlated with both the post-test scores and learning gains (but not pre-test scores), suggesting that experiences of delight may increase the likelihood of improved learning outcomes.

\section{CONCLUSIONS}

Overall, the findings in this study suggest that boredom is a powerful indicator of students' knowledge, but not necessarily indicative of learning. In particular, it is interesting that Sustained
$B O R$ correlates (negatively) more strongly to pre-test values than Sustained OFF does. This relationship changes for post-test values (where their rho values are nearly equally negative). This seems to suggest that students may learn despite high levels of boredom, but that low-knowledge learners are more prone to boredom.

Other significant patterns involving boredom (ENG-BOR, BOR$C O N, B O R-D E L, B O R-E N G, B O R-F R U, C O N-B O R$ and the negative cycle $E N G-C O N-F R U-B O R$ ) show comparable trends. In general, their correlation with the pre-test appears to be weaker than their correlation with the post-test, and none are significantly associated with learning gains.

Two patterns involving delight are more weakly associated with knowledge, and one of them (Sustained DEL) is the only pattern correlated with learning gains. However, none of the sequences that transition from delight to another affective state are statistically significant, and even BOR-DEL, which is the only significant transition to delight, is, like other sequences involving boredom, negatively associated with pre- and post-test scores.

Interestingly, even though they are relatively infrequent, the two hypothesized cycles from D'Mello and Graesser [11] appear to have a disproportionate effect on knowledge measures. Both are among the most infrequent patterns seen in the data $(0.3 \%$ and $3.2 \%$ ), and both are correlated with post-test scores. Neither is associated with learning gains, which might suggest that their relatively infrequent occurrence may be more strongly associated with prior knowledge than with learning. While both correlate to post-test scores, only the inhibitory cycle (ENG-CON-FRU-BOR) is significantly correlated to pre-test scores.

The limited prevalence (and somewhat limited effect) of the hypothesized cycles, in particular, may be attributed to methodological differences and suggests the need for further research.

The results from this study have been calculated from learning outcomes, measured from pre-test and post-test scores, and predictions from the detectors. When interpreting these results, it is important to remember that the study may be limited by the relatively lower performance of the affect detectors $\left(\mathrm{A}^{\prime}\right.$ of the detectors ranges from 0.568 to 0.725 ) in comparison to those in other learning environments, which we hypothesize is related to the open-ended nature of the Betty's Brain environment [18]. Although the results do not strongly indicate correlations with the actual emotion, the findings still indicate that there may be a correlation between the tests scores and the features of student behaviors that are associated to the different affective states.

Other methodological issues could also be impacting these results. It is possible that researchers would benefit from varying the number of steps by increasing the number of self-transitions involved in these cycles as well as by increasing the length of observation periods. Increasing the clips and amount of time considered in the analysis could allow for the discovery of more meaningful affect patterns. However, the fact that the shorter patterns showed so few statistically significant results may indicate that longer-stepped patterns will be of limited value.

If the latter is true, then researchers may need to look more carefully for specific learning contexts where these patterns are 
most effectual. For example, these results also suggest that, at least within the context of this study, affective patterns may be more related to prior knowledge than to learning gains. If this is true, interventions or design changes that help support students with relevant knowledge gaps may disrupt the boredom patterns that were prevalent among these students and increase the prevalence of other patterns thought to be relevant to learning.

\section{REFERENCES}

[1] Baker, R.S., Rodrigo, M.M.T., Xolocotzin, U. (2007). The dynamics of affective transitions in simulation problem-solving environments. International Conf. on Affective Computing and Intelligent Interaction. Springer Berlin Heidelberg, 666-67.

[2] Baker, R.S.J.d., Ocumpaugh, J. (2014) Interaction-Based Affect Detection in Educational Software. In R.A. Calvo, S.K. D'Mello, J. Gratch, A. Kappas (Eds.), The Oxford Handbook of Affective Computing. Oxford, UK: Oxford University Press.

[3] Baker, R.S., Ocumpaugh, J.L., Andres, J.M.A.L. (in press) BROMP Quantitative Field Observations: A Review. In R. Feldman (Ed.) Learning Science: Theory, Research, and Practice. New York, NY: McGraw-Hill.

[4] Benjamini, Y., \& Hochberg, Y. (1995). Controlling the false discovery rate: a practical and powerful approach to multiple testing. Journal of the royal statistical society. Series B (Methodological), 289-300.

[5] Bosch, N., \& D'Mello, S. (2017). The Affective Experience of Novice Computer Programmers. International Journal of Artificial Intelligence in Education, 1-26.

[6] Bruce P. Douglass. 1998. Statecarts in use: structured analysis and objectorientation. In Lectures on Embedded Systems, Grzegorz Rozenberg and Frits W. Vaandrager (Eds.). Lecture Notes in Computer Science, Vol. 1494. Springer-Verlag, London, 368-394. DOI: http://dx.doi.org/10.1007/3-54065193-429

[7] Calvo, R., \& D'Mello, S. (Eds.). (2011). New perspectives on affect and learning technologies. New York: Springer

[8] Craig, S., Graesser, A., Sullins, J., \& Gholson, B. (2004). Affect and learning: an exploratory look into the role of affect in learning with AutoTutor. Journal of educational media, 29(3), 241-250.

[9] D'Mello, S. K., Taylor, R., \& Graesser, A. C., 2007. Monitoring Affective Trajectories during Complex Learning. Proceedings of the 29th Annual Cognitive Science Society, 203-208.

[10] D'Mello, S., \& Graesser, A. (2011). The half-life of cognitive-affective states during complex learning. Cognition \& Emotion, 25(7), 1299-1308.

[11] D'Mello, S. Graesser, A. (2012). Dynamics of Affective States during Complex Learning. Learning and Instruction, 22, 145-157.

[12] D'Mello, S., Graesser, A. (2010). Modeling cognitive-affective dynamics with Hidden Markov Models. Proceedings of the 32nd Annual Cognitive Science Society, 2721-2726

[13] David A. Anisi. 2003. Optimal Motion Control of a Ground Vehicle. Master's thesis. Royal Institute of Technology (KTH), Stockholm, Sweden.

[14] DeFalco, J. A., Rowe, J. P., Paquette, L., Georgoulas-Sherry, V., Brawner, K., Mott, B. W., Baker, R. S., \& Lester, J. C. (2018). Detecting and addressing frustration in a serious game for military training. International Journal of Artificial Intelligence in Education, 28(2), 152-193.

[15] Hake, R. R. (1998). Interactive-engagement versus traditional methods: A six-thousand-student survey of mechanics test data for introductory physics courses. American journal of Physics, 66(1), 64-74.

[16] Ian Editor (Ed.). 2008. The title of book two (2nd. ed.). University of Chicago Press, Chicago, Chapter 100. DOI: http://dx.doi.org/10.1007/3-540-09237-4

[17] Jacques Cohen (Ed.). 1996. Special Issue: Digital Libraries. Commun. ACM 39, 11 (Nov. 1996)

[18] Jiang, Y., Bosch, N., Baker, R. S., Paquette, L., Ocumpaugh, J., Andres, J. M. A. L., Moore, Allison L., Biswas, G. (2018). Expert feature-engineering vs. deep neural networks: Which is better for sensor-free affect detection? In Proceedings of the 19th International Conference on Artificial Intelligence in Education (AIED 2018) (pp. 198-211). Berlin, Heidelberg: Springer.

[19] Karumbaiah, S., Andres, J. M. A. L., Botelho, A. F., Baker, R. S., \& Ocumpaugh, J. (2018). The Implications of a Subtle Difference in the Calculation of Affect Dynamics. In 26th International Conference for Computers in Education.
[20] Kenneth L. Clarkson. 1985. Algorithms for Closest-Point Problems (Computational Geometry). Ph.D. Dissertation. Stanford University, Palo Alto, CA. UMI Order Number: AAT 8506171.

[21] Leelawong, K., and Biswas, G. 2008. Designing Learning by Teaching Agents: The Betty's Brain System. International Journal of Artificial Intelligence in Education 18(3): 181-208.

[22] Liu, Z., Pataranutaporn, V., Ocumpaugh, J., Baker, R.S.J.d. (2013) Sequences of Frustration and Confusion, and Learning. Proceedings of the 6th International Conference on Educational Data Mining, 114-120.

[23] McQuiggan, S. W., Robison, J. L., \& Lester, J. C. (2010). Affective transitions in narrative-centered learning environments. Educational Technology \& Society, 13(1), 40-53.

[24] McQuiggan, S., Robison, J., \& Lester, J. (2008). Affective transitions in narrative-centered learning environments. In Intelligent Tutoring Systems, 490-499). Springer Berlin/Heidelberg.

[25] Meany- Daboul, M. G., Roscoe, E. M., Bourret, J. C., \& Ahearn, W. H. (2007). A comparison of momentary time sampling and partial- interval recording for evaluating functional relations. Journal of Applied Behavior analysis, 40(3), 501-514.

[26] Ocumpaugh, J., Baker, R.S., Rodrigo, M.M.T. (2015) Baker Rodrigo Ocumpaugh Monitoring Protocol (BROMP) 2.0 Technical and Training Manual. Technical Report. New York, NY: Teachers College, Columbia University. Manila, Philippines: Ateneo Laboratory for the Learning Sciences.

[27] Ocumpaugh, J., Andres, J.M., Baker, R., DeFalco, J., Paquette, L., Rowe, J., et al. (2017). Affect Dynamics in Military Trainees using vMedic: From Engaged Concentration to Boredom to Confusion. In International Conf. on Artificial Intelligence in Ed., 238-249. Springer, Cham.

[28] P. Bahl, R. Chancre, and J. Dungeon. 2004. SSCH: Slotted Seeded Channel Hopping for Capacity Improvement in IEEE 802.11 Ad-Hoc Wireless Networks. In Proceeding of the 10th International Conference on Mobile Computing and Networking (MobiCom'04). ACM, New York, NY, 112 117.

[29] Palinscar, A. S., \& Brown, A. L. (1984). Reciprocal teaching of comprehension-fostering and comprehension-monitoring activities. Cognition and instruction, 1(2), 117-175.

[30] Pekrun, R. (2006). The control value theory of achievement emotions: assumptions, corollaries, and implications for educational research and practice. Educational Psychology Review, 18(4), 315e341.

[31] Rodrigo, M.M.T., Anglo, E., Sugay, J., Baker, R. (2008). Use of unsupervised clustering to characterize learner behaviors and affective states while using an intelligent tutoring system. In International Conference on Computers in Education, 57-64.

[32] Rodrigo, M.M.T., Baker, R., Agapito, J., Nabos, J., Repalam, M., Reyes Jr, S., San Pedro, M.O.C. (2011). The effects of an embodied conversational agent on student affective dynamics while using an intelligent tutoring system. IEEE Transactions on Affective Computing, 2(4), 18-37.

[33] Rodrigo, M.M.T., Baker, R., Agapito, J., Nabos, J., Repalam, M., Reyes, S., San Pedro, M.O.C. (2012). The effects of an interactive software agent on student affective dynamics while using; an intelligent tutoring system. IEEE Transactions on Affective Computing, 3(2), 224-36.

[34] Singh, K., Granville, M., \& Dika, S. (2002). Mathematics and science achievement: Effects of motivation, interest, and academic engagement. The Journal of Educational Research, 95(6), 323-332.

[35] Vygotsky, L. S. (1978). Mind in society: The development of higher psychological processes, (M. Cole, V. John-Steiner, S. Scribner \& E. Souberman, Eds. and trans.). Cambridge, MA: Harvard University Press. 